\title{
SER ARTE: CORPO/CRIAÇÃO NOS ESPAÇOS EDUCACIONAIS ATRAVÉS DA TRANSPSICOMOTRICIDADE
}

\author{
Eduardo Costa ${ }^{1}$ \\ Fabienne Bruce ${ }^{2}$
}

\begin{abstract}
Resumo: A partir da reflexão sobre os sentidos e significados do que vem a ser uma "escola criativa" este artigo busca explicitar as relaçôes entre Psicomotricidade, Pensamento Complexo e Transdisciplinaridade a partir da proposta da Formação em TransPsicomotricidade Educacional e Clínica que capacita profissionais graduados para a sensibilizaçáo pela via do corpo das premissas da reforma do pensamento propostas por Morin, desde o casal grávido ao idoso. Para conseguir realizar tamanho empreendimento o TransPsicomotricista precisa de um mergulho intenso através da experiência corporal, em cada um dos sete saberes. Nesses 17 anos de atuação nas instituiçóes educacionais a TransPsicomotricidade busca abrir espaços reflexivos onde a corporeidade possa ser vivida com intensidade descortinando o SER ARTE, metáfora de uma vida nutrida pela poesia e pela liberdade de açóes que buscam a experiência intersubjetiva.
\end{abstract}

Palavras-chave: TransPsicomotricidade. Transdisciplinaridade. Corpo. Arte. Educação.

1 Doutor e Mestre em Ciências: Saúde da Criança - IFF/FIOCRUZ. Psicomotricista Educacional e Clinico; Fonoaudiólogo; Terapeuta Corporal. Criador e Coordenador da Formação em Transpsicomotricidade Educacional e Clínica que nasceu na UERJ e hoje tem parcerias com SINPRORIO (Rio de Janeiro), IPREDE, entre outras. Teve como mestres ao longo de sua formação, André e Anne Lapierre (FRANÇA); Mauro Vecchiato (ITÁLIA); Víctor García (ESPANHA); Bernard Aucouturier (FRANÇA), Françoise Desobeau (FRANÇA), Regina Morizot (BRASIL), Beatriz Saboya (BRASIL), dentre outras referências nacionais e internacionais em Psicomotricidade. Docente de diversas Pós-Graduações em Psicomotricidade no Brasil. Sócio Titular da ABP, Presidente da Comissão Científica do XII Congresso Brasileiro de Psicomotricidade ABP (2013), assim como Coordenador da Comissão Científica da ABP Col. Nacional, de 2011 até 2015. Consultor em TransDisciplinaridade e TransPsicomotricidade do Crescendo (RJ). Organizador dos livros: TransPsicomotricidade - WAK Editora, 2013 e Corpo Transbordante - WAK Editora, 2017. Coordenador Científico do CONGIP - Congresso ONLINE Internacional de Psicomotricidade.

2 Graduada em Letras Português/Inglês (FMU/SP). Especialização em Dificuldades de Aprendizagem: Prevenção e Reeducação (UERJ). Formação em Transpsicomotricidade Educacional (UERJ). Formação em Arte-educação (FORMAE/RJ). Formação de Brinquedista (ABBri/SP). Formanda em Clínica TransDisciplinar com Eduardo Costa. Educadora na Rede Municipal do Rio de Janeiro. Sócia Titular da Associação Brasileira de Psicomotricidade. Formadora em TransPsicomotricidade Educacional 


\title{
SER ARTE: CUERPO/CREACIÓN EN LOS ESPACIOS EDUCATIVOS A TRAVÉS DE LA TRANSPSICOMOTRICIDAD
}

Resumen: A partir de la reflexión sobre los sentidos y significados de lo que viene a ser una "escuela creativa" este artículo trata de aclararlas relaciones entre la Psicomotricidad, el Pensamiento Complejo y laTransdisciplinariedad, desde el momento en que propone la Formación en TransPsicomotricidad Educativa y Clínica, capacitando profesionales diplomados para la sensibilización por la víadel cuerpo de las premisas de la reforma del pensamiento propuestas por Morin, desde la pareja embarazada al anciano. Para lograr realizar un proyecto tan grande, el TransPsicomotricista necesita sumergirse intensamente a través de la experiencia corporal, en cada uno de los siete saberes. En estos 17 ańos de actuación en las instituciones educativas la TransPsicomotricidad se propone a crear espacios reflexivos donde la corporeidad pueda ser vivida con intensidad, despertando el SER ARTE, metáfora de una vida nutrida por la poesía y la libertad de acciones que buscan la experiencia intersubjetiva.

Palabras clave: TransPsicomotricidad. Transdisciplinariedad. Cuerpo. Arte. Educación.

\section{Introdução}

\section{Fluxos de Consciência do Devir}

\author{
“todos nascemos tão bonitos \\ a grande tragédia é que \\ nos convencem de que não somos" \\ (Rupi Kaur, 2017, p. 183)
}

Corpo. Que traz as cores dos silêncios guardados desde a gestação e caminha pela vida na busca de ser. Nascemos livres das amarras que nos fragmentam em cubículos pré-definidos onde caber socialmente é a tarefa dada desde os primeiros instantes, onde a genitália indica enfaticamente a qualidade de afetos que iremos receber. Éramos transdisciplinares, mas a cultura nos moldou a cada segundo determinando nossa maneira de estar, nossas escolhas e caminhos que percorremos. Podemos escolher algo?! Será?! Talvez a única máxima que podemos ter é que "não importa a tradição que não temos, importa a vida, os modos de vida que estamos por criar" (Mosé, 2012, p.15).

Criação. Criar ação movimentando a criança interna, afrouxando cada espaço apertado onde a poeira habita consumindo a luz que não consegue chegar nos cantos mais embolados. Fazendo das forças que nos arrastam para a dor e o sofrimento motivo estético de vida agora poética expressa através da arte. "Poesia, teatro, literatura, pintura, escultura e música oferecem-nos esse dom sublime da arte". (Morin, 2007, p. 146).

Arte. Possibilidade de liberdade ao viver a transgressão dos limites impostos pela cultura alienada, onde o mal-estar habita nas subjetividades neurotizando cada sujeito de seu corpo vibrátil sensível. Nascemos artistas e todos temos a capacidade máxima de reinvenção da vida, mas precisamos nos (re)encontrar a fim de estarmos abertos para "receber em bruto as percepções, vivê-las, elaborar-se através dos 
processos, regredindo e crescendo para fora, para o mundo". (Clark in Rolnik, 1999, p. 6).

Mundo. Contemporâneo em seu momento mais líquido da existência humana, podemos tudo, mas não sabemos o que fazer com as águas que brotam. Talvez sejamos o reflexo arcaico de uma moral rigorista estabelecida em um passado que já não existe com ares de modernidade vazia. Nos organizamos em instituições marcadas pela nossa história e a escola é uma delas. Ainda fechada em paradigmas arcaicos, onde o corpo precisa ficar aprisionado para receber informações, perdemos o mais valioso dos movimentos possíveis, a livre criação através da expressão artística, afinal "o gênio brota na brecha do incontrolável, justamente onde a loucura ronda. A criação brota da união entre as profundezas obscuras psicoafetivas e a chama viva da consciência”. (Morin, 2003, p.61).

Consciência. Luz mínima encravada na escura caverna sem fim do inconsciente, rápida e fugaz, tenta se apropriar de si ampliando suas dimensões, para então, se lançar ao mundo. Esse artigo apresenta a experiência multifacetada do trabalho realizado pela Formação em TransPsicomotricidade Educacional e Clínica abrindo um espaço para que o sujeito possa se ver enquanto um humano complexo em sua diversidade.

\section{Dos espaços educacionais e a TransPsicomotricidade}

Só corpos emocionados podem revoltar-se contra o "status quo", abrir-se, sem receio à queda dos muros disciplinares, zonas de tensão e proteção, especialmente, zonas de poder, difíceis de abdicar. (Eduardo Costa, 2013, p.116)

Um dos grandes desafios da contemporaneidade é encontrar brechas nos sistemas dados pela cultura vigente. Enquanto microcosmos da sociedade, os espaços educacionais são espelhos potentes de todo o mal-estar, há muitas angústias dadas e as pessoas sentem-se solitárias na busca por uma resposta, normalmente mágica, para resolver o problema em definitivo. Assim, se há uma criança com dificuldades de aprendizagem, por exemplo, que não consegue aprender a ler e escrever, o que fazer?! Qual a atividade 'correta' para que ela consiga realizar uma tarefa dada e, assim, pertencer ao grupo?! De quem é a responsabilidade por ela não conseguir se desenvolver naturalmente?! Da escola, dos pais, dos educadores?! Como posso interferir nisso e ajudá-la?! O que significa ser uma escola criativa ou promover uma educação criativa?

De início, talvez, pensar na palavra interferir possa nos auxiliar a construir uma ampliação de olhar. O prefixo inter indica algo que está 'entre, no meio de', seguido da palavra ferir que indica que as tentativas de encontro com o outro, no desejo de 'ajudar', pode nos levar a feri-lo. Nessa perspectiva, a palavra estimulação é utilizada, já que nela acredita-se saber o que é melhor para o sujeito fazendo com que ele seja apenas um mero espectador da ação, de algo que é colocado no meio do encontro e que vai curá-lo. Contudo, temos a palavra intervir, que contêm em si a palavra ver, ou seja, nessa nossa perspectiva, antes de qualquer ação, 
olhar para o sujeito e acompanhá-lo na sua necessidade abre um campo complexo de possibilidades de encontro. Nesse lugar/espaço onde o sujeito faz parte da ação dizendo com seu corpo o que precisa, podemos olhá-lo e deixar que ele nos afete com sua história sabendo que não temos uma resposta, mas um caminho a construir juntos.

Com isso abrimos um amplo espaço de criação, através dos corpos que podem se afetar. No caminho percorrido até agora, após dezessete anos acompanhando graduados em diversas áreas do saber na construção das competências como Psicomotricista Educacional e Clínico, temos buscado, prioritariamente, utilizar caminhos diferenciados da práxis científica em vigor nas universidades e escolas de formação e pós-graduação tanto no Brasil como no exterior na capacitação para o exercício profissional em Psicomotricidade.

Dar ênfase absoluta ao trabalho pessoal, como eixo de toda a formação, por si traz um diferencial mesmo em comparação com outras abordagens onde também há uma grande atenção a este aspecto.

Quando nos referimos a "trabalho pessoal", usando o jargão de nossa área disciplinar, propomos um mergulho no autoconhecimento, pela via da corporeidade, a partir de propostas de jogo, expressão corporal e investigação de espaços e objetos, sempre de forma intersubjetiva, realizando as leituras simbólicas das ações realizadas e das situações vividas, identificando, a partir disto, as relações com sua história de vida e marcas fundantes da personalidade.

Outra premissa que nos coloca como partidários da luta pela reforma da educação, a partir do reconhecimento da complexidade humana e dos fenômenos da natureza, é a tomada dos sete saberes necessários à educação do futuro, forjados por Morin (2003), como um currículo, princípios eixo de todas as práticas que realizamos.

Durante o percurso inicial de 19 meses, o formando é convidado a mergulhar através da experiência corporal, em cada um dos sete saberes, sendo a teorização no turno subsequente, onde a partir da estratégia chamada hoje de "sala de aula invertida", debatemos os materiais previamente analisados pelos estudantes, enviados por uma plataforma na rede.

O grande objetivo do processo formativo é acompanhar o formando na apropriação dos atributos pessoais e teóricos que sustentarão sua atuação com todos os propósitos da prática em TransPsicomotricidade. Para isso, lançamos mão de ciclos de "aprofundamento" em turmas subsequentes, onde o formando pode prosseguir na elaboração de seus fantasmas para melhor acompanhar as demandas que surgem ao se abrir um espaço de livre-expressão para os diferentes públicos da TransPsicomotricidade.

Acreditamos que esses fantasmas estão inscritos nos corpos que reproduzem comportamentos reativos aprendidos em encontros e desencontros ao longo de nossa caminhada. É preciso tomar consciência dos aprisionamentos decorrentes 
desses registros para que haja a possibilidade de realizar escolhas e as transformações que forem sentidas como necessárias.

A TransPsicomotricidade enquanto formação busca convidar esses profissionais, a partir do mergulho em seus próprios corpos, a fazer surgir o SER ARTE, deixar que seus potenciais, obscurecidos por uma educação coercitiva e adestradora, onde sentir não faz parte da vida, seja olhado profundamente e, a partir disso, poder se lançar e a compreender que o controle antes solicitado leva o sujeito a perder o que de mais precioso pode ter em sua existência:

A repressão do sentimento é um processo de insensibilização que diminui a pulsação interna do corpo, sua vitalidade, seu estado de excitação. Por esse motivo, reprimir um sentimento é reprimir todos os outros. Se reprimimos nosso medo, reprimimos nossa raiva. A repressão da raiva resulta na repressão do amor".(Lowen, 1997, p.20)

Apropriar-se dessa máxima para além de uma construção teórica é tarefa imperiosa aos educadores que afetam e são afetados diariamente pelos encontros para poderem afrouxar-se desse aprisionamento e manifestar-se em plenitude estando abertos para as demandas das crianças podendo garantir um espaço seguro de expressão criativa.

Tanto nas potências do próprio corpo, em cada relação, ou na exploração de sua funcionalidade, na força, agilidade, ritmo, velocidade, plasticidade, quanto nas potências expressivas, onde a livre criação possa ter curso, o espaço que cada prática transpsicomotora propõe consiste em um retorno ou experimentação intensa da sensoriomotricidade, plataforma onde se constituirá a personalidade e matriz que permite reformular partes da construção.

Para que o profissional habilitado nesta abordagem possa realizar um trabalho consistente e coerente com a proposta transpsicomotora necessita desenvolver competências sócio-emocionais que o possibilitem acompanhar o outro da expressividade mais limitada à mais exacerbada, sem que haja mistura entre a história pessoal do profissional e dos grupos acolhidos, gerando um campo saudável de possibilidades onde o trabalho realmente está centrado no(s) propósito(s), sem que os mesmos sejam "usados" como complemento da falta do TransPsicomotricista.

É sempre uma tarefa delicada demonstrar a importância, no enquadre da vida acadêmica, da delicadeza deste processo, que necessita de um tempo diferenciado do cronos que rege nosso cotidiano. O tempo processual da construção de competências emocionais demanda quebras narcísicas que muitas vezes geram feridas insuportáveis, que necessitam ser vividas e digeridas antes de serem elaboradas, contudo "sem uma rendição do ego narcisista, a pessoa não pode entregar-se ao amor. Sem essa entrega, a alegria é impossível” (Lowen, 1997, p.27), e o nosso trabalho também. Precisamos aceitar nossas cegueiras, sabendo que apenas na construção de uma dialógica profunda iremos nos religar compreendendo nossas diferenças enquanto sapiens/demens habitantes do planeta terra e, assim, poderemos enfrentar juntos as incertezas para compartilhar a casa comum. 
Mas essa jornada complexa demanda desejo e coragem de se ver profundamente. Nem sempre o formando também compreende uma indicação de que prossiga seu mergulho pessoal em turmas subsequentes a sua. Isto gera, muitas vezes o sentimento de reprovação e incompetência e muitos conflitos, mas para aqueles que encontram sentido na continuidade da autodescoberta, os efeitos são notáveis na potencialização de seus desejos e na assertividade de suas conquistas, mais aptos a compreender a si mesmos e consecutivamente a respeitar em profundidade as necessidades dos sujeitos que irá acompanhar.

Esse corpo que está "caixa fechada" e visa se tornar "cores no espaço", se reabilita, evocando a criança em todos nós, a capacidade de brincar, ou seja, vincular-se a partir da sintonia dos encontros prazerosos e despretensiosos, que vão libertando as amarras de uma corporeidade marcada por uma história de vida, eventualmente "catastrófica".

Como na proposição foucaultiana, tornar a vida uma obra de arte, demanda níveis de apropriação de si bastante diferenciados, onde o profundo respeito pelo outro inicie pela ruptura com as subordinações e alienações a que nos submetemos toda uma vida.

\section{"Sumi no breu da minha boca, eu mesmo me engoli" José Joffily Filho, 1982}

Percebemos também que o embrutecimento de uma vida prosaica, sem quase a possibilidade de usufruir da poesia vital, cria uma rigidez nos corpos/ subjetividades, difícil de transpor e como temos em nossos grupos de formandos muitas educadoras, que em grande número venceram múltiplos desafios apenas para estudar e se colocar socialmente, percebemos a "sobrecouraça" que se forma a partir das questões sócio-culturais de rejeição e marginalidade.

Durante o processo formativo, acompanhando cada um dos formandos, isso fica mais evidente a partir das proposições realizadas dentro do enquadre dos encontros. O processo formativo demanda $50 \%$ de sua carga horária para vivenciar o corpo, nossa proposta é, depois de viver essa livre-expressão, antes da organização verbal, oferecer um momento de representação através de propostas da arte-educação. A ideia é que as imagens encravadas nos conteúdos corporais vividos possam brotar e, aos poucos, juntamente com a tomada de consciência nessa jornada de autoconhecimento, possa se expandir em uma estética singular, recheada de simbolismos que o verbol não consegue exprimir. Acordar esse corpo até o Ser Arte, passa por esse lugar apócrifo.

Contudo, o que presenciamos, encontro após encontro, são sujeitos aprisionados em imagens estereotipadas, determinadas pelo processo educacional que vivenciaram desde os primeiros contatos com o mundo. Essas formas rígidas retratam flores da mesma espécie, como se houvesse apenas uma no mundo, as casas são pré-fabricadas como em condomínios fechados, todas ordinárias, árvores em florestas secas de vida autêntica, todas imagens de adequações desérticas a fim de pertencer ao social para não serem marcadas aos rótulos excludentes de 
inadequação. Dessa maneira, podemos inclusive afirmar que as crianças que não se submetem aos pedidos rígidos institucionais de comportamento são muito saudáveis, elas pedem para serem vistas em suas necessidades, já que não podem viver engaioladas. Vale ressaltar que essas imagens estereotipadas são bordas necessárias de sobrevivência e precisam ser desconstruídas aos poucos, já que retratam, ao mesmo tempo, o aprisionamento do corpo como um todo.

$\mathrm{Na}$ realidade carregamos marcas desde os primeiros contatos com a realidade, construímos essas bordas para nos amparar, revivê-las em um espaço simbólico e de acolhimento é a nossa proposta, tanto para as crianças, como para os educadores, as famílias, toda a comunidade escolar. Esse humano revisitado desde o espasmo involuntário à coordenação motora fina...Do quase indiferenciado ao plenamente singular...

O Sujeito/Corpo se ordenando do macro para o micro, da cabeça em direção aos pés, do centro em direção às extremidades.

O corpo que nasce enrolado em si mesmo e que aos poucos desabrocha para o mundo e o explora ativamente... a coluna vai ganhando suas curvaturas e o tônus vai possibilitando cada vez ações mais ousadas em direção à descoberta... as alavancas e suportes vão amadurecendo...e a maturação coclear e muscular possibilita equilíbrios cada vez mais precisos, em uma orientação espacial que se constitui a partir do corpo em movimento.

Tudo isso apenas vivido em plenitude no encontro potente com um adulto amoroso, que acolhe a necessidade intersubjetiva e dá suporte para vôos cada vez maiores.

Os ensaios e quedas vão gerando mais e mais liberdade e a lateralidade, o reconhecimento dos dois dimídios corporais e a percepção das funções e segmentos de seu esquema corporal vão desabrochando.

Já nesse momento as bases da Imagem Corporal estão sendo erigidas, a partir da satisfação e vazios nas relações com suas figuras de referência.

Os ritmos maternos e paternos impregnarão seu corpo, coincidindo ou divergindo com o biorítmo do bebê e gerando angústias e prazeres...As esperas e satisfações, a VOz de seus interlocutores, os rituais do banhar e do comer descortinam as noções temporais que se entrelaçam sempre com a percepção do espaço e da ação que nele é realizada.

Nas experimentações e repetições o arrastar dá lugar ao engatinhar e ao andar gerando a liberdade das mãos e a possibilidade de utilizá-las independentes...As coordenações antes mais ocupadas em organizar o corpo ereto e em movimento, podem se especializar cada vez mais...as preensões avançam de um dobra simples ao movimento de pinça, abrindo ao humano competências inimagináveis de homo faber e homo artisticus.

A carícia é o combustível mais potente como matriz de todo processo de maturação do sujeito, contudo, as frustrações inevitáveis lhes proporcionam capacidades importantes à resiliência para as adversidades e desafios...Do mesmo 
modo que as alavancas e suportes se especializam a pele e sua capacidade tátil é um envelope de religação perceptiva que nos permite o reconhecimento sutil de espaços e objetos mesmo sem a visão...Não só as mãos se organizam de modo cada vez mais elaborado, também os pés aperfeiçoam suas coordenações a ponto de poder se igualar as mãos. Veja-se os artistas que realizam com seus pés obras de extrema precisão... Os dimídios corporais por razões misteriosas amadurecem de forma distinta promovendo uma prevalência de uso... os destros e os canhotos nos mostram essa diversidade, assim como os ambidestros.

Cada pequeno avanço é sustentado pela magia das reações bioquímicas e neurológicas, adaptações que o organismo faz sempre em nome da vida... mas por vezes em direção à morte...em direção acelerada, pois ela é inexorável.

\section{O TransPsicomotricista em sua prática cotidiana}

O conhecimento pertinente é o que é capaz de situar qualquer informação em seu contexto e, se possível, no conjunto em que está inscrita. (Morin, 2015, p.15)

Se a multiplicidade é a realidade dada e se somos elementos singulares dessa engrenagem, capazes de criar novas maneiras de estar no mundo intensamente, como desconstruir os paradigmas impostos desde sempre? Como encontrar o espaço da dialógica com o todo fortalecendo o sujeito a viver sua plenitude?

A partir da trajetória pessoal de tornar-se arte - tarefa sempre inacabada, contudo, em busca de atingir níveis "suficientemente bons", parafraseando Winnicott, o TransPsicomotricista está habilitado a tratar cada instituição, onde irá se inserir, como uma teia complexa, investigando sua composição e as aberturas do sistema para o processo de sensibilização dos princípios transpsicomotores pautados nos sete saberes necessários à educação do futuro, de Edgar Morin.

A análise das relações de força e poder vigentes na instituição pautará as atitudes e intervenções do Psicomotricista representante desta abordagem que podem iniciar por diferentes meios antes da abertura de espaços livre-expressivos para os corpos do condomínio escolar ou das demais instituições.

O Transpsicomotricista irá sempre buscar as oportunidades para gerar reflexões e desnaturalizar os grandes temas alvo da reforma do pensamento linear. Seus instrumentos serão todas as formas de arte (poesia, cinema, literatura, artes plásticas, dança...) que poderão preceder ou caminhar paralelamente aos espaços onde cada grupo/turma possa viver a potência da ação frente a variados objetos e proposições abertas, onde cada sujeito possa reencontrar seus desejos e possibilidades criativas, sem o cerceamento da diretividade e condução coercitiva que habitualmente são encontradas nos ambientes escolares.

Quando o colégio já busca a ruptura com os padrões vigentes, toda a ação do Transpsicomotricista apenas irá reforçar e muitas vezes ampliar essa visão, contudo, em alguns espaços onde, apesar do desejo de mudança, ainda há muita rigidez nas relações, os encontros propostos não só às crianças mas às famílias e funcionários de 
todos os setores, proporciona uma avaliação profunda dos objetivos da Educação e uma revisão das estratégias relacionais e de aprendizagem promovidas até então.

A proposta do TransPsicomotricista é promover uma experiência profunda do 'sentir com', acreditando sempre no encontro intersubjetivo onde reside a mais profunda vinculação entre as pessoas e, em decorrência desse encontro com o outro, promover a religação das diferenças e do pertencimento, sensação essa que pode descortinar a experiência de se ser aceito integralmente em seu modo de ser/ estar no mundo e, dessa maneira, a construção de um espaço para o fortalecimento da identidade que possibilita em profundidade a revisão subjetiva. Desse lugar que o profissional se coloca para ser, encontrar a sintonia afetiva demanda dedicação e sensibilidade em direção ao outro que se deixa, ou pelo menos tenta se deixar, para ser cuidado.

Nesse movimento, nessa dança, o TransPsicomotricista também acessa seus julgamentos que não o deixam fluir nos afetos acolhedores e o controle pode acabar emergindo, mesmo sabendo que não é possível dominar o que se sente. $O$ grande desafio do TransPsicomotricista talvez seja viver o mundo das águas incontroláveis dos afetos. Talvez, inconscientemente, haja esse desejo, mas, no encontro com o outro, esse lugar é rapidamente desconstruído, visto que apenas o sujeito pode na verdade nos mostrar e ir em direção daquilo que realmente necessita, cabe ao TransPsicomotricista apenas acompanhá-lo nessa jornada realizando ruídos que podem ser aceitos ou não.

Como realizar esses ruídos para estabelecer uma sintonia afetiva intersubjetiva de potência? Como saber o ruído que se deve realizar? Como aceitar o não dado ao ruído escolhido? Não há uma receita certa, apenas construção de conceitos a partir do encontro onde a sensibilidade e a entrega corporal são os aliados de tal tarefa. Para chegar nesse lugar, muito trabalho pessoal e supervisão e, mesmo assim, sabese que esse será um trabalho sem fim, visto que somos seres humanos singulares em relação e a cada encontro podemos afetar e sermos afetados de uma maneira nunca antes experimentada e novamente precisaremos rever e questionar os ruídos a serem realizados.

A potência desse trabalho é que ao promover sistematicamente encontros tendo como base os princípios transpsicomotores, acabamos por colaborar para o avanço no encontro de saídas eficazes das situações de intolerância tão assustadoras que vem sendo nomeadas de Bullying nos últimos anos, cultivando o respeito e a valorização da diversidade, sem negar os conflitos e a face demens de todos nós, sem ideais messiânicos, contudo, promovendo a resolução pacífica de qualquer embate.

As questões de gênero, na perspectiva da equidade e da multiplicidade de identidades, também está entre nossas preocupações, sendo facilitadas quando as corporeidades são aceitas em sua autenticidade e liberdade. 


\section{Consideraçóes Finais para o início do novo novo.}

O que pode o pensamento contra todas as forças que, ao nos atravessarem, nos querem fracos, tristes, servos e tolos? Criar. (Deleuze)

$\mathrm{Na}$ contemporaneidade é comum afirmar que as ideologias terminaram, Serres (2013), afirma que na verdade as filiações que as criaram que se desfizeram e, a partir disso coloca a questão, como inventar novos laços?! Em seu livro a Polegarzinha ele reafirma o vazio como promotor de inteligência inventiva, já que a geração que chega não precisa carregar a cabeça pesada com todos os saberes acumulados. Com a metáfora dos decapitados, ele apresenta o sujeito contemporâneo leve e fluido que carrega nas mãos a fonte para qualquer pesquisa necessária durante seu processo livre de criação. Pensamos que ele nessa metáfora também coloca a liberdade aos educadores que irão receber esses novos sujeitos podendo acompanhá-los nessa criação. Contudo, outra questão surge: Quem educará os educadores?! Juntos descobriremos essa resposta, compartilhando as angústias e assumindo nossas fragilidades, permanecendo apesar dos vazios gigantescos que se abrem nos mergulhos de ampliação de consciência, lugar onde a amplitude gera o novo novo. Suportar esse lugar, onde temos apenas ilhas de certezas em um oceano de incertezas, construindo pontes de apoio, talvez nos leve a encontrar vias de criação potentes para nossa auto-análise permanente.

Nossa proposta é estar junto com as pessoas para essa construção. Tornarse um TransPsicomotricista demanda do aprendiz um imenso esforço. Nosso cotidiano nos afasta cada vez mais de nós mesmos, especialmente dos discursos de nossos corpos que são esvaziados e negados, desqualificados em seus significados mais profundos.

Ser TransPsicomotricista implica uma revisão da própria construção subjetiva e a tomada de consciência das modelagens que nossa história promoveu em nossos corpos, limitando nossa humanidade e nossa potência intersubjetiva.

Ser TransPsicomotricista é poder oferecer seu próprio corpo à tarefa de acompanhar o outro (do casal grávido ao idoso) em seus discursos não-verbais, servindo de suporte para a caminhada, fonte de referência para a superação dos obstáculos e desafios inerentes à vida incerta.

O caminho prioritário é o "trabalho pessoal", pois as técnicas e teorias só podem ser verdadeiramente compreendidas quando experimentadas pelo corpo e integradas à personalidade.

Cada vez mais percebemos a importância deste profissional em um momento de retrocessos políticos, intolerância crescente e fundamentalismos. A libertação dos corpos pode sustentar a reforma do pensamento que tanto necessitamos para enfrentar a crise planetária a que estamos todos submetidos.

O TransPsicomotricista, a partir de seu tripé ético - Formação Teóricotécnica continuada; Formação Pessoal continuada e Supervisão - pode promover questionamentos significativos sobre as formas possíveis de reformarmos as 
relações e nossa cidadania, sempre abrindo espaços para a expressão dos corpos e para a escuta de suas demandas.

A TransPsicomotricidade não é uma panaceia, contudo, pode contribuir de forma muito significativa em um mundo onde a cada dia mais nos deixamos mumificar e enrijecer... TRANSPSICOMOTRICIZE-SE!!

\section{Referências}

KAUR, Rupi. Outros jeitos de usar a boca. São Paulo: Planeta, 2017.

LOWEN, Alexander. Alegria: a entrega ao corpo e à vida. São Paulo: Summus, 1997.

MORIN, Edgar. A cabeça bem-feita: repensar a reforma, reformar o pensamento. Rio de Janeiro: Bertrand Brasil, 2015.

. Os Sete Saberes necessários à Educação do Futuro. São Paulo: Cortez. 2003.

. O método 5: a humanidade da humanidade. Porto Alegre: Sulina, 2007.

MOSÉ, Viviane. O homem que sabe. Do homo sapiens à crise da razão. Rio de Janeiro: Civilização Brasileira, 2012.

ROLNIK, Sueli. Molda-se uma alma contemporânea: o vazio-pleno de Lygia Clark. In the Experimental Exercise of freedom: Lygia Clark, Gego, Mathias Goeritz, Helio Oiticica and Mira Schendel. The Museum of Contemporary Art, Los Angeles, 1999.

SERRES, Michel. Polegarzinha. Rio de Janeiro: Bertrand Brasil, 2013. 